\title{
Silagens de milho inoculadas microbiologicamente em diferentes estádios de maturidade: perdas fermentativas, composição bromatológica e digestibilidade in vitro
}

\author{
Corn silage inoculated with lactic acid bacteria in different maturity stages: fermentative losses, \\ chemical composition and in vitro digestibility
}

\author{
Carlos Henrique Silveira Rabelo ${ }^{\mathrm{I}}$ Adauton Vilela de Rezende ${ }^{\mathrm{II}}$ Flávio Henrique Silveira Rabelo ${ }^{\mathrm{III}}$ \\ Denismar Alves Nogueira ${ }^{I V}$ Simone Silvia Senedese ${ }^{\mathrm{II}}$ Paulo de Figueiredo VieiraI \\ Célio Luiz Bernardes ${ }^{\text {II }}$ Arthur Carvalho"I
}

RESUMO

Objetivou-se com este estudo avaliar as perdas fermentativas, composição bromatológica e digestibilidade in vitro da matéria orgânica de silagens de milho produzidas em diferentes estádios de maturidade, inoculadas microbiologicamente. Aplicaram-se dois inoculantes comerciais nas silagens produzidas nos estádios $S L L, 1 / 3 L L, 1 / 2 L L, 2 / 3 L L$ e $C N$, permanecendo ainda um tratamento sem inoculação (silagem controle), configurando um esquema fatorial 3x5. A inoculação com BAL resultou em menores perdas fermentativas $(P=0,0348)$, ao passo que silagens produzidas com plantas mais secas também apresentam menores perdas de MS $(P<0,01)$. A inoculação das silagens resultou em maiores concentrações de $P B$ nas silagens produzidas nos estádios SLL, 2/3 LL e CN $(P=0,0033)$. O uso do inoculante Maize All ${ }^{\circledast}$ resultou em menor concentração de $F D N(P=0,0140)$ no estádio CN e acréscimo dos coeficientes de DIVMO quando as plantas foram colhidas com $2 / 3$ LL e CN $(P=0,0006)$. As perdas fermentativas diminuem devido à utilização dos inoculantes bacterianos e também em silagens produzidas com plantas mais secas. A aplicação de bactérias ácido-láticas (inoculante Maize All ${ }^{\circledR}$ ) em silagens de milho produzidas com plantas em estádio de maturidade mais avançado melhora a composição química e digestibilidade in vitro.

Palavras-chave: Lactobacillus plantarum, Pediococcus spp., linha de leite.

\section{ABSTRACT}

The aim of this study was to evaluate the fermentative losses, chemical composition and in vitro organic matter digestibility of corn silages produced in different maturity stages microbiologically inoculated. Two commercial inoculants were applied in the silages produced in stages $S L L, 1 / 3 L L, 1 / 2 L L$, 2/3 LL and CN, remaining an uninoculated treatment (control silage), illustrating a factorial scheme $3 \times 5$. The lactic acid bacteria (LAB) inoculation resulted in lower fermentative losses $(P=0.0348)$, whereas silages produced with dried plants present lower DM losses $(P<0.01)$. Because of inoculant application, there was higher concentrations of $C P$ in the silages produced in stages $S L L, 2 / 3 L L$ and $C N(P=0.0033)$ and concentration lower of $N D F(P=0.0140)$ in $C N$ stage because of the Maize All ${ }^{\circledR}$ inoculant. This inoculant provided increase in the IVOMD coefficients when the plants were harvested with $2 / 3 L L$ and $C N(P=0.0006)$. Fermentative losses decreased because of the use of microbial inoculants, and this fact it is also observed in silages produced with dried plants. Application of lactic acid bacteria (Maize All ${ }^{\circledR}$ inoculant) in corn silages produced with plants harvested in more advanced stages of maturity improve the chemical composition and in vitro digestibility.

Key words: Lactobacillus plantarum, milk line, Pediococcus spp.

\section{INTRODUÇÃO}

O milho apresenta características desejáveis ao processo de ensilagem, devido à grande produção de matéria seca (MS) por hectare, associado ao adequado conteúdo de nutrientes para promover boa fermentação dentro do silo (MCDONALD et al., 1991). Todavia, nem sempre os resultados obtidos estão de acordo com as expectativas dos produtores, por negligências cometidas durante a ensilagem, sendo necessário adotar estratégias que visem a melhorar o processo de fermentação e assegurar o maior valor nutritivo das silagens produzidas, além de reduzir as perdas durante a fermentação.

\footnotetext{
'Universidade Estadual Paulista (UNESP), Via de Acesso Prof. Paulo Donato Castellane, s/n, 14884-900, Jaboticabal, SP, Brasil. E-mail: carlos.zoo@hotmail.com. Autor para correspondência.

"Universidade José do Rosário Vellano (UNIFENAS), Alfenas, MG, Brasil.

"IIEscola Superior de Agricultura "Luiz de Queiroz" (ESALQ), Piracicaba, SP, Brasil.

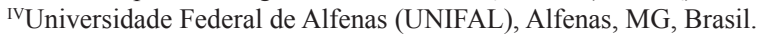


Nesse sentido, a utilização de inoculantes contendo bactérias ácido-láticas (BAL) homofermentativas, como Enterococcus faecium, e espécies de Pediococcus, além de BAL heterofermentativas facultativas (Lactobacillus plantarum) (HOLZER et al., 2003), têm por intuito aumentar a população destes microrganismos no silo. A expectativa é que esses microrganismos dominem o processo fermentativo e preservem maior quantidade de nutrientes nas silagens, devido à rápida produção de ácido láctico e, consequente queda do pH (FILYA, 2003), implicando em maiores coeficientes de digestibilidade in vitro, além de reduzir perdas de MS ocorridas nesta fase. Dessa forma, a atuação de alguns microrganismos indesejáveis ao processo de conservação são inibidos, como as leveduras, que metabolizam os açúcares à etanol e $\mathrm{CO}_{2}$, e as bactérias do gênero Clostridium, responsáveis pelo aumento da proteólise (MCDONALD et al., 1991).

Outra estratégia interessante consiste na colheita do milho em diferentes estádios de maturidade fisiológica da planta, cujo efeito é determinante na qualidade do material ensilado. Em decorrência do desenvolvimento fenológico, os teores de MS e fibra aumentam e as perdas de MS diminuem (VILELA et al., 2008), embora, em alguns casos, o teor de fibra pode ser reduzido, devido à maior participação de grãos na massa ensilada. Contudo, o efeito associativo entre estádio de maturidade e aplicação de inoculantes microbianos tem sido pouco estudado no meio científico (HU et al., 2009).
Portanto, buscou-se investigar, neste estudo, as perdas fermentativas, composição bromatológica e digestibilidade in vitro da matéria orgânica de silagens produzidas em diferentes estádios de maturidade, inoculadas microbiologicamente.

\section{MATERIAL E MÉTODOS}

O estudo foi conduzido na Universidade José do Rosário Vellano/UNIFENAS, Alfenas - MG. Foi avaliado o híbrido comercial BM3061, semeado a $5 \mathrm{~cm}$ de profundidade, utilizando-se 10 sementes $/ \mathrm{m}$ linear em espaçamento de $80 \mathrm{~cm}$ entre linhas. $\mathrm{Na}$ adubação, utilizou-se o formulado NPK 10-20-10 na quantidade de $400 \mathrm{~kg}$ por hectare. Decorridos 20 dias do plantio, realizou-se o desbaste, deixando 5 plantas por metro linear (20 plantas por linha), obtendo-se um estande médio de 62.500 plantas ha-1.

Realizou-se a colheita do milho nos seguintes estádios de maturidade: grãos sem linha de leite (SLL); 1/3 de linha de leite (LL); 1/2 LL; 2/3 LL; camada negra - CN (Tabela 1). As plantas foram cortadas manualmente a $10 \mathrm{~cm}$ da superfície do solo e desintegradas em picadeira estacionária (partículas com tamanho médio de $2,0 \mathrm{~cm}$ ) após estabelecimento do ponto ideal de colheita (análise visual do avanço da LL nos grãos). Em seguida, aplicaram-se os inoculantes (dosados de acordo com as recomendações dos fabricantes) na forragem com borrifador, utilizando água destilada. Utilizaram-se dois inoculantes: Silobac ${ }^{\circledR} \rightarrow$ contém $L$. plantarum

Tabela 1 - Características agronômicas e composição bromatológica das plantas de milho no momento da ensilagem, nos cinco estádios de maturidade avaliados.

\begin{tabular}{|c|c|c|c|c|c|}
\hline Item $^{*}$ & SLL & 1/3 LL & $1 / 2 \mathrm{LL}$ & 2/3 LL & $\mathrm{CN}$ \\
\hline Corte (dias) & 114 & 121 & 126 & 133 & 140 \\
\hline Espigas $\left(\mathrm{kg} \mathrm{t}^{-1}\right)^{1}$ & - & 321,0 & 310,2 & 342,9 & 334,3 \\
\hline Grãos $\left(\mathrm{kg} \mathrm{t}^{-1}\right)^{1}$ & - & 182,1 & 215,4 & 220,5 & 235,3 \\
\hline $\operatorname{MS}\left(\mathrm{g} \mathrm{kg}^{-1}\right.$ de MV) & 259,1 & 295,3 & 315,6 & 338,8 & 384,2 \\
\hline MO & 956,8 & 958,4 & 959,1 & 956,7 & 956,1 \\
\hline Cinzas & 43,1 & 41,5 & 40,8 & 43,2 & 43,8 \\
\hline PB & 67,2 & 63,1 & 67,4 & 66,2 & 65,1 \\
\hline FDN & 645,0 & 621,8 & 607,3 & 586,0 & 600,9 \\
\hline FDA & 305,9 & 281,4 & 277,6 & 303,2 & 305,4 \\
\hline Lignina & 62,4 & 62,9 & 60,8 & 69,4 & 59,1 \\
\hline
\end{tabular}

${ }^{*} \mathrm{SLL}=$ sem linha de leite; $\mathrm{LL}=$ linha de leite; $\mathrm{CN}=$ camada negra.

${ }^{1}$ Participação de espigas e grãos em relação à planta inteira.

${ }^{2} \mathrm{MS}=$ matéria seca; $\mathrm{MO}=$ matéria orgânica; $\mathrm{PB}=$ proteína bruta; FDN = fibra em detergente neutro; FDA = fibra em detergente ácido 
e P. pentosaceus $\left(2,5 \times 10^{10}\right.$ unidades formadoras

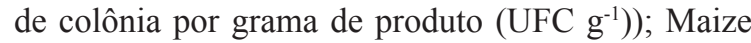
$\mathrm{All}^{\circledR} \rightarrow$ contém $\boldsymbol{E}$. faecium e $\boldsymbol{L}$. plantarum $(1,0 \mathrm{x}$ $10^{10} \mathrm{UFC} \mathrm{g}^{-1}$ de produto), P. acidilactici $\left(1,0 \times 10^{9}\right.$ UFC $\mathrm{g}^{-1}$ de produto), enzimas amilolíticas $(1,5 \%)$, celulolíticas $(1,5 \%)$ e proteolíticas $(2,0 \%)$. Parte da forragem ensilada permaneceu sem a aplicação de inoculantes (silagem controle). Esse processo foi repetido nos cinco estádios de maturidade estudados. Silos experimentais de tubos PVC (capacidade de $4 \mathrm{~L}$ ), providos de válvula tipo Bunsen e $0,5 \mathrm{~kg}$ de areia (determinar perdas por efluente) foram usados em cada tratamento. As perdas de MS (PMS) foram calculadas de acordo com JOBIM et al. (2007).

Após 55 dias da ensilagem, os silos foram abertos para leitura do $\mathrm{pH}$ e determinação dos teores de MS, cinzas, matéria orgânica (MO) e nitrogênio total (NT) (AOAC, 1996), em que a proteína bruta (PB) foi obtida pelo produto entre o NT e o fator 6,25. Determinaram-se ainda os teores de fibra em detergente neutro (FDN), fibra em detergente ácido (FDA) (VAN SOEST et al., 1991), lignina (VAN SOEST \& ROBERTSON, 1985) e carboidratos totais (CHOT) (SNIFFEN et al., 1992).

Uma subamostra das silagens produzidas (secas em estufa de circulação forçada a $55^{\circ} \mathrm{C}$ e moída em peneira com crivos de $1 \mathrm{~mm}$ ) foi destinada ao ensaio in vitro de produção de gás por 72 horas (MAURÍCIO et al., 1999) para determinar os coeficientes de digestibilidade in vitro da matéria orgânica (DIVMO) (MENKE et al., 1979):

DIVMO $(\mathrm{g} / \mathrm{g}$ de $\mathrm{MO})=14,88+((0,889$

$*$ gas 24$)+(0,045 * \mathrm{~PB})+(0,065 * \mathrm{CZ}))$ em que:

DIVMO $=$ coeficientes de digestibilidade in vitro da matéria orgânica; gas 24 = produção de gás in vitro em 24 horas (ml 0,2 $\mathrm{g}^{-1}$ de $\left.\mathrm{MS}\right) ; \mathrm{PB}=$ proteína bruta ( $\mathrm{g}$ $\mathrm{kg}^{-1}$ de MS); $\mathrm{CZ}=\operatorname{cinzas}\left(\mathrm{g} \mathrm{kg}^{-1}\right.$ de MS).

O delineamento experimental utilizado foi inteiramente casualizado em esquema fatorial $3 \times 5$, com quatro repetições por tratamento. Os resultados obtidos foram submetidos à análise de variância, utilizando-se o software SISVAR ${ }^{\circledR}$, e as médias comparadas pelo teste de Scott-Knott, adotando-se uma significância de 5\%.

\section{RESULTADOS E DISCUSSÃO}

Silagens produzidas com $1 / 3$ e $2 / 3$ LL apresentaram maior massa específica $(\mathrm{P}=0,0010)$, enquanto o menor valor foi obtido com a ensilagem de plantas no estádio $\mathrm{CN}$. A silagem produzida no estádio SLL apresentou menor $\mathrm{pH}(\mathrm{P}=0,0010)$ devido à maior atividade de água (Tabela 2). Silagens com maior teor de MS tendem a estabilizar o processo fermentativo em $\mathrm{pH}$ mais elevado, pois há menor produção de ácidos em função do aumento na pressão osmótica (MCDONALD et al., 1991).

Reduziram-se as PMS com a aplicação dos inoculantes Silobac ${ }^{\circledR}$ e Maize $\mathrm{All}^{\circledR}(\mathrm{P}=0,0348)$ (Tabela 2). As BAL presentes nesses inoculantes são homoláticas (produzem ácido lático como produto final da fermentação) e reduzem rapidamente o $\mathrm{pH}$ das silagens, evitando a atuação de microrganismos indesejáveis durante o processo de fermentação. Além disso, as BAL homofermentativas fermentam glicose e convertem cada molécula desse açúcar em duas de ácido lático, possibilitando recuperação teórica de $100 \%$ e $99,0 \%$ de MS e energia, respectivamente (KUNG et al., 2003).

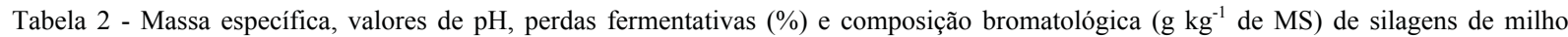
produzidas em diferentes estádios de maturidade fisiológica e inoculadas com BAL.

\begin{tabular}{|c|c|c|c|c|c|c|c|}
\hline Item $^{*}$ & $\mathrm{ME}^{2}$ & $\mathrm{pH}$ & Gás & PMS & MS & FDA & Lignina \\
\hline \multicolumn{8}{|l|}{ Inoculante } \\
\hline Controle & $573^{\mathrm{a}}$ & $3,97^{\mathrm{a}}$ & $0,03^{\mathrm{a}}$ & $7,95^{\mathrm{a}}$ & $302,3^{\mathrm{a}}$ & $294,8^{\mathrm{a}}$ & $52,2^{\mathrm{a}}$ \\
\hline Silobac & $583^{\mathrm{a}}$ & $3,94^{\mathrm{a}}$ & $0,03^{\mathrm{a}}$ & $6,17^{\mathrm{b}}$ & $301,1^{\mathrm{a}}$ & $304,6^{\mathrm{a}}$ & $50,3^{\mathrm{a}}$ \\
\hline Maize All & $577^{\mathrm{a}}$ & $3,93^{\mathrm{a}}$ & $0,02^{\mathrm{a}}$ & $6,20^{\mathrm{b}}$ & $305,1^{\mathrm{a}}$ & $276,6^{\mathrm{b}}$ & $53,7^{\mathrm{a}}$ \\
\hline \multicolumn{8}{|c|}{ Estádio de maturidade } \\
\hline SLL & $570^{\mathrm{b}}$ & $3,81^{\mathrm{b}}$ & $0,02^{\mathrm{b}}$ & $8,96^{\mathrm{a}}$ & $240,1^{\mathrm{e}}$ & $310,6^{\mathrm{a}}$ & $49,0^{\mathrm{a}}$ \\
\hline $1 / 3 \mathrm{LL}$ & $606^{\mathrm{a}}$ & $3,92^{\mathrm{a}}$ & $0,05^{\mathrm{a}}$ & $8,17^{\mathrm{a}}$ & $275,5^{\mathrm{d}}$ & $268,9^{\mathrm{b}}$ & $47,6^{\mathrm{a}}$ \\
\hline $1 / 2 \mathrm{LL}$ & $577^{\mathrm{b}}$ & $3,98^{\mathrm{a}}$ & $0,03^{\mathrm{b}}$ & $7,56^{\mathrm{a}}$ & $294,9^{c}$ & $310,0^{\mathrm{a}}$ & $58,5^{\mathrm{a}}$ \\
\hline 2/3 LL & $594^{\mathrm{a}}$ & $3,97^{\mathrm{a}}$ & $0,02^{\mathrm{b}}$ & $4,86^{\mathrm{b}}$ & $325,4^{\mathrm{b}}$ & $289,6^{\mathrm{b}}$ & $52,0^{\mathrm{a}}$ \\
\hline $\mathrm{CN}$ & $541^{\mathrm{c}}$ & $4,05^{\mathrm{a}}$ & $0,02^{\mathrm{b}}$ & $4,31^{\mathrm{b}}$ & $378,3^{\mathrm{a}}$ & $280,9^{\mathrm{b}}$ & $53,3^{\mathrm{a}}$ \\
\hline CV $(\%)$ & 6,27 & 3,36 & 59,12 & 35,46 & 4,95 & 9,46 & 18,36 \\
\hline
\end{tabular}

${ }^{*} \mathrm{SLL}=$ sem linha de leite; $\mathrm{LL}=$ linha de leite $\mathrm{CN}=$ camada negra.

${ }^{1}$ Médias seguidas de mesma letra na coluna não diferem entre si pelo teste de Scott-Knott $(\alpha=0,05)$.

${ }^{2} \mathrm{ME}=$ massa específica $\left(\mathrm{kg}\right.$ de massa verde $\left./ \mathrm{m}^{3}\right) ; \mathrm{PMS}=$ perdas de matéria seca; $\mathrm{MS}=$ matéria seca; FDA = fibra em detergente ácido. 
Silagens produzidas nos estádios $2 / 3 \mathrm{LL}$ e $\mathrm{CN}$ apresentaram menores PMS totais, devido à menor produção de efluente $(\mathrm{P}<0,01)$, decorrente do acréscimo no teor de MS $(\mathrm{P}<0,01)$ nestes estádios (Tabelas 2 e 3 ). As silagens produzidas nos estádios $1 / 2$ LL, 2/3 LL e CN estiveram dentro ou próximas à faixa de MS ideal (300 a $370 \mathrm{~g} \mathrm{~kg}^{-1}$ de massa verde) para que ocorresse adequado processo fermentativo e, com isso, diminuíssem as PMS e valor nutritivo, devido ao rompimento da membrana das células (efeito da compactação) e vazamento do conteúdo celular.

Desdobrando-se a interação entre inoculação e estádio de maturidade $(\mathrm{P}<0,01)$, constatou-se que as silagens produzidas nos estádios SLL e 1/3 LL apresentaram menores concentrações de MO, devido à aplicação dos inoculantes Silobac ${ }^{\circledR}$ e Maize $A_{11}^{\circledR}$ (Tabela 3), o que pode representar maior atividade dos microrganismos contidos nestes inoculantes durante o processo fermentativo. O L. plantarum e espécies de Pediococcus atuam em uma faixa de $\mathrm{pH}$ mais baixa do que os demais microrganismos presentes na massa ensilada (WOOLFORD, 1984), utilizando compostos solúveis (principalmente açúcares) como substratos para seu desenvolvimento, implicando maior produção de ácido lático (FILYA, 2003).

A inoculação das silagens produzidas nos estádios SLL, 2/3 LL e CN resultou em maiores concentrações de PB (interação entre os fatores de estudo $(\mathrm{P}=0,0033)$, tabela 3$)$. Estes resultados são interessantes, pois permitem inferir que os inoculantes foram eficientes em controlar a população de microrganismos indesejáveis que causam a proteólise durante a fermentação, principalmente bactérias do gênero Clostridium.

Tabela 3 - Desdobramento da interação entre silagens de milho produzidas em diferentes estádios de maturidade fisiológica e inoculação com BAL.

\begin{tabular}{|c|c|c|c|c|c|c|}
\hline Silagem $^{1}$ & SLL & $1 / 3 \mathrm{LL}$ & $1 / 2 \mathrm{LL}$ & 2/3 LL & $\mathrm{CN}$ & $\mathrm{CV}(\%)$ \\
\hline \multicolumn{7}{|c|}{ 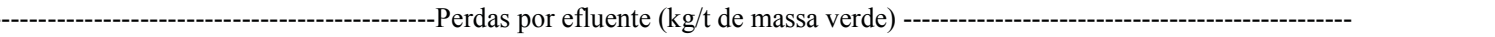 } \\
\hline Controle & $28,72^{\text {Aa }}$ & $19,88^{\mathrm{Aa}}$ & $10,08^{\mathrm{Ab}}$ & $6,41^{\mathrm{Ab}}$ & $1,74^{\mathrm{Ab}}$ & \\
\hline Silobac & $35,43^{\mathrm{Aa}}$ & $21,87^{\mathrm{Ab}}$ & $6,72^{\mathrm{Ac}}$ & $2,00^{\mathrm{Ac}}$ & $1,47^{\mathrm{Ac}}$ & \\
\hline Maize All & $14,25^{\mathrm{Ba}}$ & $25,28^{\mathrm{Aa}}$ & $18,12^{\mathrm{Aa}}$ & $1,68^{\mathrm{Ab}}$ & $1,70^{\mathrm{Ab}}$ & 66,32 \\
\hline \multicolumn{7}{|c|}{---Cinzas $\left(\mathrm{g} \mathrm{kg}^{-1}\right.$ de MS $)$} \\
\hline Controle & $43,6^{\mathrm{Ba}}$ & $39,2^{\mathrm{Bb}}$ & $44,0^{\mathrm{Aa}}$ & $37,2^{\mathrm{Ab}}$ & $45,3^{\mathrm{Aa}}$ & \\
\hline Silobac & $55,1^{\mathrm{Aa}}$ & $40,9^{\mathrm{Bc}}$ & $47,0^{\mathrm{Ab}}$ & $40,6^{\mathrm{Ac}}$ & $36,3^{\mathrm{Bc}}$ & \\
\hline Maize All & $42,4^{\mathrm{Ba}}$ & $46,8^{\mathrm{Aa}}$ & $39,6^{\mathrm{Ab}}$ & $35,3^{\mathrm{Ab}}$ & $40,4^{\mathrm{Bb}}$ & 9,81 \\
\hline \multicolumn{7}{|c|}{ 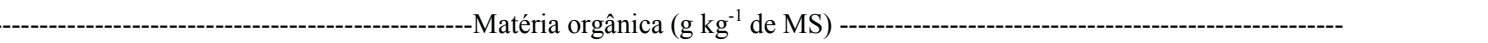 } \\
\hline Controle & $956,3^{\mathrm{Ab}}$ & $960,7^{\mathrm{Aa}}$ & $955,9^{\mathrm{Ab}}$ & $962,7^{\mathrm{Aa}}$ & $954,6^{\mathrm{Bb}}$ & \multirow{6}{*}{0,43} \\
\hline Silobac & $944,8^{\mathrm{Bc}}$ & $959,1^{\mathrm{Aa}}$ & $952,9^{\mathrm{Ab}}$ & $959,3^{\mathrm{Aa}}$ & $963,7^{\mathrm{Aa}}$ & \\
\hline Maize All & $957,5^{\mathrm{Ab}}$ & $953,1^{\mathrm{Bb}}$ & $960,4^{\mathrm{Aa}}$ & $964,6^{\mathrm{Aa}}$ & $959,5^{\mathrm{Aa}}$ & \\
\hline & & --Proteín & $\mathrm{g}^{-1}$ de MS & & & \\
\hline Controle & $55,5^{\mathrm{Bb}}$ & $61,6^{\mathrm{Ab}}$ & $69,7^{\mathrm{Aa}}$ & $52,9^{\mathrm{Bb}}$ & $59,2^{\mathrm{Bb}}$ & \\
\hline Silobac & $62,4^{\mathrm{Aa}}$ & $64,5^{\mathrm{Aa}}$ & $65,8^{\mathrm{Aa}}$ & $72,0^{\mathrm{Aa}}$ & $67,5^{\mathrm{Aa}}$ & \\
\hline \multirow[t]{2}{*}{ Maize All } & $67,1^{\mathrm{Ab}}$ & $65,2^{\mathrm{Ab}}$ & $61,3^{\mathrm{Ab}}$ & $66,5^{\mathrm{Ab}}$ & $75,3^{\text {Aa }}$ & 9,66 \\
\hline & & Carboidra & $\mathrm{kg}^{-1} \mathrm{de} \mathrm{N}$ & & & \multirow{4}{*}{1,00} \\
\hline Controle & $872,2^{\mathrm{Aa}}$ & $865,1^{\mathrm{Ab}}$ & $856,2^{\mathrm{Ab}}$ & $880,8^{\text {Aa }}$ & $866,3^{\mathrm{Ab}}$ & \\
\hline Silobac & $859,2^{\mathrm{Aa}}$ & $862,5^{\mathrm{Aa}}$ & $863,3^{\mathrm{Aa}}$ & $855,4^{\mathrm{Ba}}$ & $863,9^{\mathrm{Aa}}$ & \\
\hline \multirow[t]{2}{*}{ Maize All } & $861,2^{\mathrm{Aa}}$ & $861,0^{\mathrm{Aa}}$ & $867,1^{\mathrm{Aa}}$ & $870,0^{\mathrm{Aa}}$ & $854,7^{\mathrm{Aa}}$ & \\
\hline & - & a em dete & ro $\left(\mathrm{g} \mathrm{kg}^{-1}\right.$ & ----------- & - & \multirow[b]{4}{*}{5,91} \\
\hline \multirow{3}{*}{$\begin{array}{l}\text { Controle } \\
\text { Silobac } \\
\text { Maize All }\end{array}$} & $526,5^{\mathrm{Aa}}$ & $559,0^{\mathrm{Aa}}$ & $556,1^{\mathrm{Ba}}$ & $532,3^{\mathrm{Ba}}$ & $546,7^{\mathrm{Aa}}$ & \\
\hline & $533,6^{\mathrm{Ab}}$ & $522,7^{\mathrm{Ab}}$ & $591,8^{\mathrm{Aa}}$ & $607,5^{\mathrm{Aa}}$ & $550,3^{\mathrm{Ab}}$ & \\
\hline & $531,2^{\mathrm{Ab}}$ & $538,0^{\mathrm{Ab}}$ & $532,4^{\mathrm{Bb}}$ & $581,6^{\mathrm{Aa}}$ & $491,5^{\mathrm{Bb}}$ & \\
\hline \multirow{4}{*}{$\begin{array}{l}\text { Controle } \\
\text { Silobac } \\
\text { Maize All }\end{array}$} & ------------ & ade in vitr & a orgânic & O) ------- & ------- & \\
\hline & $0,719^{\mathrm{Ab}}$ & $0,782^{\mathrm{Aa}}$ & $0,731^{\mathrm{Ab}}$ & $0,653^{\mathrm{Bc}}$ & $0,643^{\mathrm{Bc}}$ & \\
\hline & $0,726^{\mathrm{Ab}}$ & $0,645^{\mathrm{Cc}}$ & $0,666^{\mathrm{Bc}}$ & $0,782^{\mathrm{Aa}}$ & $0,664^{\mathrm{Bc}}$ & \\
\hline & $0,706^{\mathrm{Ab}}$ & $0,721^{\mathrm{Bb}}$ & $0,699^{\mathrm{Ab}}$ & $0,769^{\mathrm{Aa}}$ & $0,747^{\mathrm{Aa}}$ & 4,55 \\
\hline
\end{tabular}

${ }^{*} \mathrm{SLL}=$ sem linha de leite; $\mathrm{LL}=$ linha de leite $\mathrm{CN}=$ camada negra.

${ }^{1}$ Médias seguidas de mesma letra maiúscula (dentro de colunas) e minúscula (dentro de linhas) não diferem entre si pelo teste de Scott-Knott $(\alpha=0,05)$ 
A silagem inoculada com Silobac ${ }^{\circledR}$ no estádio 2/3 LL apresentou menor valor de CHOT ( $\mathrm{P}=0,0124)$, não havendo efeito dos inoculantes nos demais estádios de maturidade (Tabela 3). Com relação à concentração de FDN, de maneira geral, verificou-se acréscimo em todas as silagens até o estádio 2/3 LL ( $\mathrm{P}=0,0140)$, havendo uma redução no estádio $\mathrm{CN}$, devido à maior participação de grãos na massa ensilada (Tabela 1). Com o avanço na maturidade fisiológica das plantas, há alterações morfológicas importantes, como diminuição da porção citoplasmática da célula (proteínas, lipídeos, carboidratos solúveis e minerais solúveis) e aumento da parede celular (SULLIVAN, 1973).

Comparando-se os valores de FDN entre plantas e silagens, em todos os estádios de maturidade avaliados neste trabalho, percebem-se menores teores após o processo de ensilagem. Isso poderia sugerir que a silagem apresenta melhor valor nutritivo em relação à planta que lhe deu origem, entretanto, não é o que acontece, pois o FDN "residual" da silagem, embora seja menor do que a planta é de pior qualidade, pois apresenta maior lignificação e menor conteúdo de componentes potencialmente digestíveis (MCDONALD et al., 1991). Portanto, o processo de conservação não confere melhor valor nutritivo à silagem em relação à planta (VAN SOEST, 1994).

A aplicação do inoculante Maize $\mathrm{All}^{\circledR}$ implicou a queda de FDA ( $\mathrm{P}=0,0088)$, o que está relacionado à presença da enzima celulase neste produto, a qual age sobre a celulose contida na parede celular, rompendo as ligações do tipo $\beta$ 1-4 glicosídicas (BEAUCHEMIN et al., 2003), liberando açúcares. Dessa forma, o inoculante mostrouse eficiente no intuito de reduzir a fração fibrosa, podendo ocorrer maior fermentação da massa ensilada devido à liberação de açúcares adicionais, uma vez que as BAL não degradam componentes da parede celular ou qualquer outro componente que limite a digestibilidade (MUCK, 1993).

Do mesmo modo, silagens produzidas nos estádios 1/3 LL, 2/3 LL e CN apresentaram menor concentração de FDA ( $\mathrm{P}=0,0015)$ (Tabela 2), o que está de acordo com os resultados encontrados por STPIERRE et al. (1983) em silagem de milho colhida em diferentes estádios de maturidade.

No entanto, a concentração de lignina não foi alterada $(\mathrm{P}>0,05)$, o que está de acordo com os resultados obtidos por SILVA et al. (2005). A lignina presente na parede celular da forragem está negativamente associada com a digestão da fibra, devido ao arranjo estrutural e tipo de ligações covalentes com a hemicelulose, o que torna esta fração responsável pela redução na qualidade da planta (MOORE \& JUNG, 2001).

Em razão dos diferentes teores de umidade da massa ensilada, constatou-se que a população de BAL, adicionada por meio de inoculantes, pode se comportar de maneira diferente por causa da disponibilidade de substratos para fermentação e possivelmente pela atividade de água. Dessa forma, espera-se que a população de BAL possa dominar o processo de fermentação e assegurar melhores características das silagens produzidas.

Nesse sentido, encontraram-se maiores coeficientes de DIVMO $(\mathrm{P}=0,0006)$ quando as silagens sem inoculantes (controle) foram produzidas nos estádios SLL, 1/3 LL e 1/2 LL (Tabela 3). Em estudos de digestibilidade in vitro, é esperado que os coeficientes diminuam em estádios de maturidade mais avançados, devido à maior lignificação das plantas (RUSSELL et al., 1992).

A aplicação do inoculante Maize $\mathrm{All}^{\circledR}$ nos estádios 2/3 LL e CN proporcionou maiores coeficientes de DIVMO, pois este inoculante contém enzimas amilolíticas, assim como a celulase, que atuam sobre o amido e celulose, respectivamente, e auxiliam na degradação destas frações durante o processo digestivo. Outro ponto interessante está relacionado à sobrevivência de BAL em condições in vitro (WEINBERG et al., 2003), em que estas podem promover maiores coeficientes de digestibilidade do alimento, em virtude de uma possível manipulação no perfil de microrganismos presentes no rúmen e/ou maior preservação de nutrientes durante o processo fermentativo.

O efeito da aplicação de inoculantes microbianos sobre a digestibilidade da MS foi retratado por MUCK \& KUNG (1997), em que os autores sumarizaram resultados de 82 experimentos e demonstraram que, em aproximadamente $30 \%$ dos casos, houve uma resposta positiva dos inoculantes sobre esta variável.

\section{CONCLUSÃO}

Silagens de milho inoculadas com bactérias ácido-láticas apresentam menores perdas de matéria seca durante o processo de fermentação. Do mesmo modo, há menores perdas fermentativas em silagens produzidas com plantas mais secas (estádios 2/3 LL e CN). A aplicação de bactérias ácido-láticas (especialmente o inoculante Maize All ${ }^{\circledR}$ ), em silagens de milho produzidas com plantas em estádio de maturidade mais avançado, melhora a composição bromatológica e digestibilidade in vitro. 


\section{REFERÊNCIAS}

ASSOCIATION OF OFFICIAL ANALYTICAL CHEMIST, AOAC. Official Methods of Analysis. 16ed. AOAC, Washington, DC, USA, 1996. 1015p.

BEAUCHEMIN, K.A. et al. Use of exogenous fibrolytic enzymes to improve feed utilization by ruminants. Journal of Animal Science, v.81, n.2, p.37-47, 2003. Disponível em: <http://www. journalofanimalscience.org/content/81/14_suppl_2/E37.full. pdf + html $>$. Acesso em: 12 fev. 2013.

FILYA, I. The effect of Lactobacillus buchneri and Lactobacillus plantarum on the fermentation, aerobic stability, and ruminal degradability of low dry matter corn and sorghum silages. Journal of Dairy Science, v.86, p.3575-3581, 2003.

HOLZER, M. et al. The role of Lactobacillus buchneri in forage preservation. TRENDS in Biotechnology, v.21, n.6, p.282-287, 2003.

HU, W. et al. The effect of Lactobacillus buchneri 40788 or Lactobacillus plantarum MTD- 1 on the fermentation and aerobic stability of corn silages ensiled at two dry matter contents. Journal of Dairy Science, v.92, p.3907-3914, 2009.

JOBIM, C.C. et al. Avanços metodológicos na avaliação da qualidade da forragem conservada. Revista Brasileira de Zootecnia, v.36, p.101-119, 2007. Disponível em: <http://dx.doi. org/10.1590/S1516-35982007001000013>. Acesso em: 17 abr. 2013. doi: 10.1590/S1516-35982007001000013.

KUNG JR., L. et al. Silage additives. In: BUXTON, D.R.; MUCK, R.E.; HARRISON, J.H. (Eds.) Silage Science and Technology. Wisconsin: ASA; CSSA; SSSA, 2003. p.305-360.

MAURICIO, R.M. et al. A semi-automated in vitro gas production technique for ruminant feedstuff evaluation. Animal Feed Science and Technology, v.79, p.321-330, 1999. Disponível em: <http:/ www.cnpgl.embrapa.br/nova/4workshop/artigos/2.pdf $>$. Acesso em: 22 abr. 2013

MCDONALD, P. et al. The Biochemistry of Silage. 2.ed. New York: Chalcombe Publications, 1991. 339p.

MENKE, K.H. et al. The estimation of the digestibility and metabolisable energy content of ruminant feeding stuffs from the gas production when they are incubated with rumen liquor in vitro. Journal of Agricultural Science, v.93, p.217-222, 1979. Disponível em: < http://dx.doi.org/10.1017/S0021859600086305>. Acesso em: 23 abr. 2013. doi: 10.1017/S0021859600086305.

MOORE, K.J.; JUNG, H.J.G. Lignin and fiber digestion. Journal of Range Management, v.54, n.4, p.420-430, 2001. Disponível em: <http://www.jstor.org/discover/10.2307/4003113?uid=3737 664\&uid $=2 \&$ uid $=4 \&$ sid $=21102915016601>$. Acesso em: 15 abr 2013. doi: $10.2307 / 4003113$.
MUCK, R.E. The role of silage additives in making high quality silage. In: SILAGE PRODUCTION FROM SEED TO ANIMAL, 1993, New York. Proceedings... New York: NRAES, n.67, 1993. p.106-116.

MUCK, R.E.; KUNG JR., L. Effects of silage additives on ensiling. In: SILAGE:FIELD TO FEEDBUNK. Pennsylvania. Proceedings... New York: NRAES, 1997, n.99, p.187-199.

RUSSELL, J.R. et al. Nutritive value and ensiling characteristics of maize herbage as influenced by agronomic factors. Animal Feed Science and Technology, v.38, p.11-24, 1992.

SILVA, A.V. et al. Composição bromatológica e digestibilidade in vitro da matéria seca de silagens de milho e sorgo tratadas com inoculantes microbianos. Revista Brasileira de Zootecnia, v.34, n.6, p.1881-1890, 2005. Disponível em: <http://dx.doi. org/10.1590/S1516-35982005000600011>. Acesso em: 12 jan. 2013. doi: 10.1590/S1516-35982005000600011.

SNIFFEN, C.J. et al. A net carbohydrate and protein system for evaluating cattle diets: carbohydrate and protein availability. Journal of Animal Science, v.70, n.12, p.35623577, 1992. Disponível em: <http://www.animal-science.org/ content/70/11/3562.full.pdf>. Acesso em: 22 abr. 2013.

ST-PIERRE, N.R. et al. Effects of stage of maturity and frost on nutritive value of corn silage for lactating dairy cows. Journal of Dairy Science, v.66, p.1466-1473, 1983.

SULLIVAN, J.T. Drying and storing Herbage as Hay. International: Chemistry and Biochemistry of Herbage (Eds.): BUTLER, G.W.; BAILEY, R.W. Academic Press. London and New Yord, 1973, p.4.

VAN SOEST, P.J. et al. Symposium: carbohydrate methodology, metabolism and nutritional implications in dairy cattle. Journal of Dairy Science, v.74, n.10, p.3583-3597, 1991

VAN SOEST, P.J. Nutritional ecology of the ruminant. 2.ed. Ithaca: Cornell University, 1994. 476p.

VAN SOEST, P.J.; ROBERTSON, J.B. Analysis of forages and fibrous foods. Cornell University, 1985. 202p.

VILELA, H.H. et al. Valor nutritivo de silagens de milho colhido em diversos estádios de maturação. Revista Brasileira de Zootecnia, v.37, n.7, p.1192-1199, 2008. Disponível em: < http:// dx.doi.org/10.1590/S1516-35982008000700008>. Acesso em: 18 abr. 2013. doi: 10.1590/S1516-35982008000700008.

WEINBERG, Z.G. et al. The survival of silage inoculant lactic acid bacteria in rumen fluid. Journal of Applied Microbiology, v.94, p.1066-1071, 2003. Disponível em: <http://onlinelibrary.wiley. com/doi/10.1046/j.1365-2672.2003.01942.x/full>. Acesso em: 03 mai. 2013. doi: 10.1046/j.1365-2672.2003.01942.

WOOLFORD, M.K. The Silage Fermentation. New York: Marcel Dekker, 1984. 305p. 